Martz, D. (2003). Behavioral treatment for a female engaging in autoerotic asphyxiation. Clinical Case Studies, 2(3): 236-242. (July 2003) Published by Sage (ISSN: 1534-6501). doi:10.1177/1534650103002003006

\title{
Behavioral Treatment for a Female Engaging in Autoerotic Asphyxiation
}

Denise Martz

\begin{abstract}
Once thought to be a phenomenon only practiced by men, autoerotic asphyxiation, a form of sexual masochism that is life-threatening, has been documented in women. This case study presents a 22-year-old college female with comorbid depression and avoidant personality disorder complaining of the use of autoerotic asphyxiation during masturbation. This female was a virgin and reported that asphyxiation by use of a ligature had always been used since puberty during masturbation and was necessary for her to obtain orgasm. This behavior was conceptualized within an obsessive-compulsive cycle. Covert systematic desensitization using her written sexual fantasy across 10 psychotherapy sessions was able to neutralize the power of the fantasy to elicit orgasm. Subsequent behavioral deterrents and experimentation with a vibrator enabled this female to reach orgasm without engaging in asphyxiation. Following this success, psychotherapy continued to focus on managing her depression and avoidance tendencies.
\end{abstract}




\section{THEORETICAL AND RESEARCH BASIS}

More commonly called "autoerotic asphyxiation," the DSM-IV, under the diagnosis of sexual masochism, describes hypoxyphilia as "involving sexual arousal by oxygen deprivation obtained by means of chest compression, noose, ligature, plastic bag, mask, or chemical" (e.g., volatile nitrate) (American Psychiatric Association, 1994, p. 529). This practice causes disruption of blood supply to the brain and consequential diminished oxygenation and increased carbon dioxide retention that are described subjectively to result in light-headedness, disinhibition, exhilaration, and giddiness that reinforce masturbatory pleasure (Resnick, 1972). Due to equipment failures and loss of consciousness during this practice, accidental deaths sometimes occur. Once thought to be a phenomenon only practiced by men (Edmonson, 1972), nowcases of autoerotic asphyxiation, including fatalities, have been documented in women (Burgess \& Hazelwood, 1983; Byard \& Bramwell, 1988; Danto, 1980; Hazelwood, Dietz, \& Burgess, 1983; Sass, 1975).

Speculations pertaining to the origins of this behavior include the following: (a) abnormal breast-feeding during infancy causing hypoxia linked with erections (Resnick, 1972), (b) childhood physical and/or sexual abuse, particularly if it involved torture or asphyxiation that became classically conditioned to arousal and sexual response (Diamond, Inalla, \& Ernulf 1990; Friedrich \& Gerber, 1994), and (c) guilt-driven desires to punish oneself for erotic behavior that is considered taboo and forbidden (Money \& Lamacz, 1989). Regardless of its origins, the pairing of these behaviors and enhanced orgasm is a common factor that can be conceptualized as producing a classically conditioned response that is reinforced over time. In fact, autoerotic asphyxiation has been conceptualized like obsessive-compulsive disorder, whereby the thought of conducting a taboo or forbidden behavior gives rise to distress (Rachman\&Hodgson, 1980). The distress is then reduced by performance of the compulsive masturbatory behavior, which is both positively reinforced by the pleasurable sensations and negatively reinforced by tension reduction (i.e., distress about conducting the behavior decreases when it was just performed). If this is followed by distress (e.g., in the form of guilt and shame), then a build-up of distress over time will reinitiate the cycle.

\section{CASE STUDY}

"Sue" is a 22-year-old college female who was transferred to me by another therapist who was relocating. The previous treatment began after a hospitalization for suicidal ideation and focused for 20 months on building rapport and managing depression and obsessive-compulsive disorder symptoms (i.e., independent from autoerotic asphyxiation) through cognitive-behavioral techniques. Per her therapist's report, Sue had made steady but slow progress during this course of psychotherapy. The previous therapist was aware of Sue's autoerotic asphyxiation but had not treated it directly. On transfer, it took several sessions to build rapport with me as Sue was severely shy and harbored traits of avoidant personality disorder (i.e., any suggestions to make social overtures were resisted). While discussing her depression and the autoerotic asphyxiation, Sue expressed shame, guilt, and remorse for the behavior (i.e., not the masturbation, only the asphyxiation) and believed it was the primary source of her low self-esteem. Hence, she wanted to address this first in therapy. 


\section{PRESENTING COMPLAINTS}

Sue's presenting complaints included depression, loneliness, and weekly use of asphyxiation through strangulation during masturbation.

\section{HISTORY}

Sue was the firstborn of several children and raised in a Christian family. Her parents were described as somewhat distant emotionally. Sue reported academic success but denied any close relationships with peers. She had, however, experienced closer social ties in the past that ended in her feeling rejected. Sue denied any physical or sexual abuse as a child and was a virgin. She reported a lifelong fascination with ropes and strangulation and even acted out these fantasies with her dolls as a child. During her early teen years, Sue reported onset of masturbation that always involved strangulation. These asphyxiation episodes occurred approximately once per week, and strangulation with a ligature was always necessary for her to reach orgasm. While exploring antecedents to the behavior, Sue reported that occasionally she would view a scene in a book or a movie that involved hanging and this would prompt the behavior. However, most of the time, it appeared that stress and anxiety or her sex drive preceded the behavior. Sue reported always engaging in fantasy/imagery that involved being strangled to death while masturbating and using the ligature. Sue stated the pattern would include only one orgasm and she would experience a sense of physical tension release and a reduction of the distress built up by the obsessions. However, these pleasant feelings would soon be replaced by guilt, disgust, and remorse for having succumbed to the behavior. Interestingly, origins of these negative emotions seemed to have resulted from the fact that Sue had always assumed that such asphyxiation was abnormal. Likewise, she had thoroughly researched the topic via the Internet on her own and the knowledge that others practiced this same behavior was of no comfort to her. She was aware of the dangerousness of asphyxiation but appeared to be more concerned with the fact that the behavior was "disgusting" rather than potentially lethal.

\section{ASSESSMENT}

Prior to the intake interview, Sue completed the PRIME-MD (Primary Care Evaluation of Mental Disorders) (Spitzer et al., 1994), which indicated several somatic symptoms, depression, and anxiety. During the first session, she presented as very introverted and reticent to talk about these issues and appeared to be grieving the loss of her previous therapist. Her responses to the semistructured interview indicated dysthymia with previous major depressive episodes, some scattered anxiety symptoms, and sexual masochism. Since the psychiatric hospitalization, Sue had been under the care of a psychiatrist and was prescribed Celexa $60 \mathrm{mg}$ qd during the daytime and Remeron $60 \mathrm{mg}$ qhs to facilitate sleep at night. After several sessions, Sue was administered the MCMI-III (Millon Clinical Multiaxial Inventory-III) (Millon, Davis, \& Millon, 1997), a measure of psychological symptoms and personality functioning, that indicated severe avoidance and self-defeating tendencies along with symptoms of anxiety and depression. 


\section{CASE CONCEPTUALIZATION}

Because sexual response is a physiological behavior that responds to environmental stimuli, it was conceptualized within a behavioral model. Sue's initial sexual responses during masturbation in her teen years as well as consistent pairing of ligatureinduced asphyxiation to these physical sensations made this necessary for her to reach orgasm. Likewise, maintenance of this behavior could be explained within an operant circle. Specifically, anxiety and obsessional thoughts or sex drive, which had no other outlet, would precede masturbation. Consequently, orgasm could not be achieved unless strangulation was used. Tension would be released and pleasure experienced thereby both negatively and positively reinforcing respectively the use of strangulation for orgasm. Then, guilt and shame resulting from her evaluation of this behavior would heighten anxiety and create attempts at avoidance behavior (e.g., thought suppression and denial of her sex drive). However, a buildup of anxiety or her natural sex drive of an external cue would eventually prompt the behavior again within about 1 week. Hence, both classical conditioning and operant conditioning help us to see the powerful contingencies of this behavioral cycle.

\section{COURSE OF TREATMENT AND ASSESSMENT OF PROGRESS}

Sue was first asked to write out the fantasy evoked during masturbation. She, initially, was reluctant to do this but did so with support and a thorough rationale. I discussed procedures of desensitization, whereby we would work gently up a hierarchy, and flooding, whereby we would exposure her continuously to the fantasy. Sue chose the desensitization approach. She was briefly trained in relaxation and imagery prior to the beginning of these exposures. Exposures occurred across 10 therapy sessions spread out over 3 months. Initially, these involved her reading the fantasy daily to herself at home. Next, these involved me reading the fantasy to myself, then reading one fourth of the writing aloud to her, then reading one half, then reading the full fantasy aloud to her once per session, and finally twice per session. Sue would routinely become intensely anxious during these exposure sessions and regularly reported an SUDs (subjective units of distress) rating of 10 , which rarely fluctuatedmuch lower, on a 1 to10scale. It was during these difficult sessions that I would offer a nonsexual hug, which she always accepted, at the end of the sessions. Subsequent to the first exposure session, Sue reported a particularly intense episode that occurred at home. She reported heightened anxiety and had to intensify the strangulation to the point that she experienced a transient heart arrhythmia shortly after. This scared her to the point of considering medical intervention that she did not obtain. After this session, we reviewed a safety protocol that ensured her ligature was designed to relax if she lost consciousness. Other issues such as managing her depression and encouragement to establish social contacts were also discussed during these exposure sessions.

Sue's written fantasy situated her naked in a room with an amorphous other individual whom she reported was a man. This man would tie her hands and feet together with rope, then wrap a noose around her neck, throw the rope over a beam, and slowly pull the rope to hang her. She reported usually achieving orgasm at the point she envisioned her toes no longer touching the floor and she was gasping for air and about to die. Notably, the fantasy was devoid of any "normal" sexual behaviors between two individuals. During several sessions, I offered some interpretation of the fantasy such as Sue's desire to have a partner who would know her secret and oblige her in her sexual fantasy. 
We also discussed the fact that she trusted this person, essentially with her life, as it was his responsibility to release the noose at the completion of her sexual activity. Sue had never had such an intimate relationship in her life but strongly desired one.

After the 10 exposure sessions, Sue reported that the fantasy was diminished during masturbation and consequently she had ceased use of asphyxiation. However, she was frustrated by the inability to achieve orgasm any other way at this time. This suggests her orgasmic capacity had been under the stimulus control of asphyxiation. During several of these sessions, we discussed other behavioral deterrents such as removal of strings, ropes, tape, and other cords from her apartment. Next, Sue purchased a vibrator, per my suggestion, and was able to successfully reach orgasm with this device. During the subsequent session while she described this success, Sue exhibited the most positive affect witnessed throughout her course of therapy. After this occasion, Sue reported one slip, where she again used asphyxiation, during a time when the batteries of the device ran out of power.We contracted that she would engage in an emergency phone call to me if this temptation returned, and she agreed to keep extra batteries on hand.

\section{COMPLICATING FACTORS}

The behavioral techniques used to treat this autoerotic asphyxiation resulted in the most rapid progress in this course of psychotherapy. The fact that Sue presented as deeply introverted with well-ingrained avoidance behaviors complicated the management of her depression. Albeit infrequent, Sue described some of her most rewarding moments in life as involving emotionally close contact with others. However, the introversion and avoidance patterns were keeping her from initiating these circumstances. The fact that Sue was a virgin and had never experienced sexual contact and successful orgasm with another person hindered her ability to establish a normal sexual fantasy during masturbation, which at this point no longer involved asphyxiation.

\section{MANAGED CARE CONSIDERATIONS}

Fortunately, Sue had a rather liberal insurance policy that allowed a substantial number of sessions per year. When we arrived at the limit, a request for further sessions, emphasizing this progress in treating the autoerotic asphyxiation and the necessity of additional sessions to continue to treat the depression, was submitted and granted until the fiscal year renewed. Keep in mind, it was customary for us to meet bimonthly, and her insurance might not have allowed weekly sessions. Thus, this type of behavioral program is considered longer term and would be more of a challenge with a company that requires a renewal every four to seven sessions.

\section{FOLLOW-UP}

Treatment continued after Sue successfully extinguished the autoerotic asphyxiation. Despite my assurance that people have a variety of sexual stimuli evoked for sexual fantasies, she complained that her only remaining sexual fantasies were deviant (i.e., some continued focus on devices that could be used for strangulation), even though she was no longer practicing these behaviors during masturbation. Again, the fact that she was a virgin and therefore had negligible learning experiences or alternate material for sexual fantasies complicated this. Therefore, we continued to focus on counter conditioning that involved her masturbating using the vibrator while engaging in deviant fantasies 
and purposefully looking at heterosexual stimuli (i.e., which she obtained per my request) just prior to orgasm. In addition, cognitive-behavioral techniques and interpersonal therapy techniques were continued to help Sue manage and alleviate her depression and reduce her social avoidance. It was anticipated that such psychotherapy would sustain indefinitely as long as we cooperated with the parameters of her insurance.

\section{TREATMENT IMPLICATIONS OF THE CASE}

This case study, to the author's knowledge, is the first successful course of therapy for autoerotic asphyxiation in a female that has been published. It suggests that this behavior succumbs to behavioral contingencies much like any normal sexual behavior. Use of an exposure technique can be used to extinguish the power of such a taboo and forbidden behavior so as to render it impotent.

\section{RECOMMENDATIONS TO CLINICIANS}

Due to the life-threatening nature of this behavior, psychotherapists should regularly screen for this practice in their clients. Furthermore, if a client is performing such a behavior, the therapist should ensure that he/she has designed the ligature in a failsafe manner until the behavior is extinguished. I did not have the forethought to address this issue early in our therapy and was quite thankful that my treatment, particularly the initial exposures, did not result in Sue's death. Because I had only treated one case similar to this before, I consulted the literature and sought out peer supervision for support on this case. This would be advised for any therapists treating such cases.

\section{REFERENCES}

American Psychiatric Association. (1994). Diagnostic and Statistical Manual (4th ed.). Washington, DC: Author.

Burgess, A., \& Hazelwood, R. (1983). Autoerotic asphyxial deaths and social network response. American Journal of Orthopsychiatry, 53, 166-170.

Byard, R., \& Bramwell, N. (1988). Autoerotic death in females: An underdiagnosed syndrome. American Journal of Forensic Medical Pathology, 9, 252-254.

Danto, B. (1980). A case of female autoerotic death. American Journal of Forensic Medical Pathology, 1, 117-121.

Diamond, M., Inalla, S.,\& Ernulf, A. (1990). Asphyxiophilia and autoerotic death. Hawaii Medical Journal, 49, pp. 11-16, 24.

Edmonson, J. (1972). A case of sexual asphyxia without fatal termination. British Journal of Psychiatry, 121, 437-438.

Friedrich, W., \& Gerber, P. (1994). Autoerotic asphyxia: The development of a paraphilia. Journal of the American Academy of Child and Adolescent Psychiatry, 33, 970-975. 
Hazelwood, R., Dietz, P., \& Burgess, A. W. (1983). Autoerotic fatalities. Lexington, MA: D. C. Heath. Millon, T., Davis, R., \& Millon, C. (1997). MCMI-III: Millon Multiaxial Inventory III. Minneapolis, MN: NCS.

Money, J., \& Lamacz, M. (1989). Vandalized love maps. Buffalo, NY: Prometheus.

Rachman, S., \& Hodgson, R. (1980). Obsessions and compulsions. Englewood Cliffs, NJ: Prentice Hall.

Resnick, H. (1972). Eroticized repetitive hangings: A form of self-destructive behavior. American Journal of Psychotherapy, 26, 4-21.

Sass, F. (1975). Sexual asphyxia in the female. Journal of Forensic Science, 2, 181-185.

Spitzer, R. L., Williams, J. B.W., Kroenke, K., Linzer, M., deGruy, F.V., Hahn, S. R., et al. (1994). Utility of a new procedure for diagnosing mental disorders in primary care: The PRIMEMD 1000 study. Journal of the American Medical Association, 272, 1749-1756. 